\title{
Incidence and cost of treatment-emergent comorbid events in insured patients with chronic hepatitis $C$ virus infection: a retrospective cohort study
}

Sandhya Sapra', Eunice Chang ${ }^{2}$, Michael S Broder ${ }^{2^{*}}$ and Gilbert L'Italien ${ }^{1,3}$

\begin{abstract}
Background: Treatment-emergent comorbid events (TECS) are common In patients initiating treatment with pegylated interferon alpha (PEG-IFN-alfa) and ribavirin for chronic hepatitis $\mathrm{C}$ virus (HCV) infection. The purpose of this study was to estimate the incidence and incremental cost of these events.

Methods: In a retrospective cohort analysis of healthcare claims, we studied patients with HCV who were newly treated with PEG-IFN-alfa/ribavirin between 2006 and 2008. TECs were defined by new medical/pharmacy claims for predefined conditions in the 12 months after treatment initiation. The net incremental cost of the TECs was the difference between baseline and follow-up costs for these comorbidities and their treatment, excluding PEG-IFN-alfa/ribavirin costs.

Results: Of 3,795 newly treated patients, 1,269 (mean age 50.2, 36.2\% female) met the selection criteria. New TECs were common, with $61.6 \%$ of patients having $\geq 1$ event. Anemia was identified in $29.2 \%$ of patients, fatigue in $16.4 \%$, depression in $11.5 \%$, and neutropenia in $11.0 \%$. The mean incremental cost for the predefined TEC in the postindex period was $\$ 6,377$ ( $\$ 2,782$ for medical and $\$ 3,595$ for pharmacy claims).

Conclusions: In an insured US cohort with chronic HCV infection, TECS with PEG-IFN-alfa/ribavirin were common and increased costs by approximately $\$ 6,000$ per treated patient. This estimate may be conservative because it excludes indirect costs. Costs might increase with new regimens that include a protease inhibitor because additional TECs may be expected. Better-tolerated therapies that reduce the financial burden on the healthcare system and improve patient experience are needed.
\end{abstract}

Keywords: Insurance claims, Retrospective study, Pegylated interferon alpha, Ribavirin

\section{Background}

Chronic hepatitis $\mathrm{C}$ virus (HCV) infection, with a worldwide prevalence of $2 \%-3 \%$ [1], causes substantial loss of life and reduces quality of life in those who are infected [2]. Although the screening of blood products has reduced the incidence of $\mathrm{HCV}$ infection in developed countries, there is a long latency period before the disease becomes symptomatic and thus large numbers of new cases will continue to be identified over the coming years.

\footnotetext{
* Correspondence: mbroder@pharllc.com

${ }^{2}$ Partnership for Health Analytic Research, LLC, 280 S. Beverly Drive, Suite 404, Beverly Hills, CA, USA

Full list of author information is available at the end of the article
}

Estimates suggest that about half of the 3.1 million US patients infected with HCV are unaware of their infection and only a small fraction have been treated [3-5].

Under optimal conditions, treatment of chronic HCV infection with pegylated interferon alpha (PEG-IFN-alfa) and ribavirin dual therapy produces sustained virologic response (SVR) of above $50 \%$ in patients with $\mathrm{HCV}$ infection [6,7]. For patients with the most common HCV genotype (GT) in the US, GT-1, 48 weeks of PEG-IFN-alfa/ ribavirin results in an SVR in 45\%-50\%, whereas in patients with GT-2 and GT-3, 24 weeks of PEG-IFN-alfa/ribavirin results in an SVR in $80 \%$. Nearly all patients who achieve a SVR are cured of infection [8] and have a reduced risk of 
hepatocellular carcinoma and death [9]. However, treatment with PEG-IFN-alfa/ribavirin causes numerous adverse events including fatigue, flulike symptoms, gastrointestinal disturbances, psychological symptoms, and hematologic abnormalities [10]. These adverse events lead to decreased adherence, dose reduction, and early discontinuation. Patients who are able to maintain at least $80 \%$ adherence to their drug regimen have the highest likelihood of achieving a SVR, but treatment-emergent comorbid events (TECs) commonly limit adherence [10-12].

In the initial treatment of $\mathrm{HCV}$ infection, the addition of a protease inhibitor (telaprevir or boceprevir) to PEG-IFN-alfa/ribavirin (triple therapy) significantly improved SVR [13,14]. However, adverse events were reported at higher rates among users of triple therapy than among users of PEG-IFN-alfa/ribavirin [13,14]. Although a small subset of patients receiving triple therapy who have a rapid response can receive a shorter course of treatment, the $47 \%-77 \%$ premature discontinuation rates of PEG-IFN-alfa/ribavirin reported in clinical care settings $[15,16]$ would likely be similar with triple therapy.

Premature discontinuation of treatment and nonadherence may cause viral resistance and increase costs. Although combination therapies to treat HCV may cost between $\$ 23,000$ and $\$ 78,000$ per year (depending on GT, patient weight, and drug selected) [17], treatment with PEG-IFN-alfa/ribavirin has been shown to be cost effective when patients are cured [18]. In addition, nonadherent patients have higher $\mathrm{HCV}$-related medical (i.e., excluding medication) costs than adherent patients [19]. However, despite their frequency and effect on treatment success, little is known about the cost associated with adverse events due to treatment with PEG-IFN-alfa/ ribavirin itself [20]. The objective of this study was to estimate the incidence of TECs and the incremental costs of treating these events in insured patients initiating PEG-IFN-alfa/ribavirin treatment for chronic $\mathrm{HCV}$ infection. Secondary objectives were to explore, in a managed care population, the rate of discontinuation of PEG-IFN-alfa/ribavirin therapy and the temporal pattern of the costs of these TECs.

\section{Methods}

\section{Study design and data source}

This study was a retrospective cohort analysis that used data from the i3 Ingenix LabRx database spanning the 4-year period from $7 / 1 / 05$ to $6 / 30 / 09$. This database is a Health Insurance Portability and Accountability Act (HIPAA)-compliant administrative claims database of 8-10 million covered lives, representing all major regions of the US. The database contains deidentified adjudicated pharmacy and medical claims submitted for payment by providers, healthcare facilities, and pharmacies and includes information on physician visits, medical procedures, hospitalizations, drugs dispensed, and tests performed. Healthcare charges are reported (medical, inpatient, and pharmacy) in this database, but paid claims and costs are not. Also available are member enrollment and benefit information as well as limited patient, provider, and hospital demographic information. Since the study did not involve direct contact with human subjects, did not involve an intervention, and did not involve collection of any identifiable patient information, Institutional Review Board (IRB) approval was not required.

\section{Study population}

The study included treatment-naive patients with $\mathrm{HCV}$ infection who began treatment with PEG-IFN-alfa/ ribavirin during a 2-year period between 7/1/06 and 06/ 30/08. PEG-IFN-alfa and ribavirin were identified using National Drug Codes. The date of the first medication fill for PEG-IFN-alfa/ribavirin within this period was defined as the index date. The 24-month study period included 12 months before and 12 months after the index date. Treatment-naive $\mathrm{HCV}$-infected patients were defined as those who did not fill any prescriptions for PEG-IFN-alfa prescription for at least 12 months before the first such fill. HCV infection was defined by the presence of at least 1 medical claim with an ICD-9-CM (International Classification of Diseases, 9th Revision, Clinical Modification) code for HCV (070.41x, 070.44, 070.51, 070.54, 070.7x) during the preindex period.

Patients were excluded if they were $<18$ years of age or if they were not continuously enrolled during the 24-month study period. We also excluded individuals who initiated therapy at a dose not recommended by the manufacturer [21-24]. Finally, we excluded patients with certain medical claims during the preindex period, including those with an ICD-9-CM code for hepatitis $\mathrm{B}(070.2 \mathrm{x}, 070.3 \mathrm{x})$,or hematologic malignancies for which interferon may have been indicated [leukemia (204. $x x-208 . x x)$, Hodgkin's lymphoma (201.xx), non-Hodgkin's lymphoma (200, 202.0-202.2, 202.8), multiple myeloma (203.0-203.1, 238.6), acute lymphocytic leukemia (204.0), chronic lymphocytic leukemia (204.1), acute nonlymphocytic leukemia including acute myeloid leukemia (205.0), acute monocytic leukemia (206.0), chronic myeloid leukemia (205.1), or other leukemias (204.2, 204.8-204.9, 205.2, 205.8-205.9, 206.1-206.2, 206.8-206.9, 207.8, 208.0-208.2, 208.8-208.9)].

\section{Outcome measures}

The primary outcome variable was net incremental cost, which was calculated as the difference between preindex and postindex cost for a prespecified list of TECs (see following paragraph) and their treatments, excluding the cost of PEG-IFN-alfa/ribavirin therapy. Charges for TECs 
were taken from medical claims consistent with one of these events or pharmacy claims with National Drug Codes for medications to treat the events. Charges for visits lacking a code for one of the listed TECs were not included. New TECs were defined by a medical or pharmacy claim in the postindex period that was not present in the preindex period.

TECs were grouped as blood disorders (anemia, neutropenia, thrombocytopenia), gastrointestinal disorders (nausea/vomiting, diarrhea), endocrine disorders (diabetes, hyperthyroidism, hypothyroidism), psychiatric disorders (depression, anxiety disorders, bipolar disorders, insomnia), skin and subcutaneous disorders (alopecia, skin rash), and other disorders (dyspnea, fatigue, headache). Medications used to treat TECs were grouped similarly and included those to treat blood disorders (epoetin alfa, darbepoetin, filgastrim, and eltrombopag), endocrine disorders (antidiabetes medications and thyroid agents), psychiatric disorders (anxiolytics, antidepressants, antipsychotics/antimanics, and hypnotics), skin disorders (topical steroids), and other (antimigraine).

Secondary outcomes included the incidence of new TECs, timing of such TECs, and the rate of discontinuation of PEG-IFN-alfa/ribavirin therapy. PEG-IFN-alfa/ribavirin therapy was considered to be discontinued if there were no prescription fills for both medications for at least 60 days. The date of discontinuation was defined as the last day the patient had both PEG-IFN-alfa and ribavirin available, based on the days of supply as reported in the pharmacy claims. If PEG-IFN-alfa and ribavirin were discontinued on different dates, the earlier date was used.

\section{Covariates}

Other measures included patient age, gender, race, geographic region, and the presence of human immunodeficiency virus (HIV) infection/acquired immune deficiency syndrome (AIDS). Because physician specialty may impact cost and resource use, we identified the specialty of each patient's usual care physician using a validated method. The specialty of the physician prescribing therapy was not directly identifiable in the claims database. Instead, the method counts all claims for evaluation and management services and identifies the physician specialty with the largest plurality of such claims [25]. Physician specialty was assigned using claims from the preindex period.

\section{Sensitivity analyses}

The recommended PEG-IFN-alfa/ribavirin treatment duration is either 24 or 48 weeks, depending on $\mathrm{HCV}$ GT. Claims data are used to process payments and generally do not contain clinical information such as test results. However, GT data were available for a small subset of study subjects and we thus explored discontinuation rates for this subset in a sensitivity analysis. In another sensitivity analysis, we restricted the group of patients analyzed to those who were treated beyond 28 weeks of PEG-IFN-alfa/ribavirin treatment, under the assumption that they had GT-1 infection.

\section{Statistical analysis}

For descriptive analysis, percentages, medians, means, and standard deviations were calculated for all baseline variables. We reported the percentage of patients with any new TEC as well as the percentage with a new event for each TEC. We reported the mean and standard deviations for TEC charges in both the pre- and postindex periods and for net incremental TEC charges. Treatment discontinuation was reported as the proportion of patients who no longer had PEG-IFN-alfa/ribavirin available at successive 4-week intervals. Charges for TECs were also stratified by duration of therapy. All data transformations and statistical analyses were performed using SAS version 9.2 (SAS Institute, Cary, NC).

\section{Results}

We identified 3,795 patients with $\mathrm{HCV}$ infection who were newly treated with PEG-IFN-alfa/ribavirin during the study period. Of these, 1,269 met the inclusion criteria (Table 1), The most common reason for exclusion (2,274 patients) was lack of continuous enrollment for 24 months. One hundred thirty-eight patients were excluded because of a co-occurring diagnosis of hepatitis $\mathrm{B}$ or a hematologic malignancy, 16 because they lacked an $\mathrm{HCV}$ diagnosis in the pre-index period, and 85 because they had an initial dose of PEG-IFN-alfa/ribavirin other than one of those recommended by the manufacturer. Most of the included subjects were male (63.8\%), with $85.1 \%$ between the ages of 40 and 59 years old (mean age, 50.2 years). Over half $(55.6 \%)$ the patients were from the South. Only $3.5 \%$ of patients in this sample were coinfected with HIV. The most common treating physician specialty was gastroenterology (32.4\%), followed by family practice (28.5\%) and internal medicine (25.2\%).

Table 2 shows the proportion of patients who had a diagnosis recorded for each TEC before beginning treatment (preindex period) and the proportion with a diagnosis recorded for the TEC while they were receiving treatment (postindex period). In addition, the proportion of patients who had a new diagnosis while receiving treatment (e.g., no such diagnosis in the preindex period, followed by a diagnosis in the postindex period) is shown. These newly diagnosed conditions are considered to be TECs. Disorders of blood were observed in $14.3 \%$ of patients in the preindex period and in $41.2 \%$ of patients in the postindex period. In the postindex period, $35.2 \%$ of patients had a new diagnosis of a blood disorder and new psychiatric events were 


\begin{tabular}{|c|c|}
\hline Characteristic & No. $(\%)$ of insured patients $(n=1269)$ \\
\hline Age, mean (SD), y & $50.2(7.7)$ \\
\hline \multicolumn{2}{|l|}{ Age group (y) } \\
\hline $18-29$ & $31(2.4)$ \\
\hline 30-39 & $61(4.8)$ \\
\hline 40-49 & $405(31.9)$ \\
\hline 50-59 & $675(53.2)$ \\
\hline 60-69 & $91(7.2)$ \\
\hline $70+$ & $6(0.5)$ \\
\hline Female & $459(36.2)$ \\
\hline \multicolumn{2}{|l|}{ Region } \\
\hline East & $123(9.7)$ \\
\hline Midwest & $242(19.1)$ \\
\hline South & $705(55.6)$ \\
\hline West & $199(15.7)$ \\
\hline \multicolumn{2}{|c|}{ Type of health benefits } \\
\hline Commercial & $1,244(98.0)$ \\
\hline Medicaid-HMO & $25(2.0)$ \\
\hline HIV/AIDS & $44(3.5)$ \\
\hline
\end{tabular}

AIDS, acquired immune deficiency syndrome; $\mathrm{HCV}$, hepatitis $\mathrm{C}$ virus; HIV, human immunodeficiency virus; PEG-IFN-alfa, pegylated interferon alpha.

observed in $20.1 \%$, endocrine events in $12.1 \%$, and gastrointestinal events in $12.0 \%$. Most $(61.6 \%)$ patients had at least 1 newly diagnosed TEC. The most common TECs were anemia (29.2\%), fatigue (16.4\%), depression (11.5\%), neutropenia (11.0\%), insomnia (8.98\%), nausea/ vomiting (8.35\%), skin rash (7.64\%), hypothyroidism (6.93\%), thrombocytopenia (6.70\%), dyspnea (5.99\%), and headache (5.91\%).

The mean net incremental charge for the predefined TEC in the postindex period was $\$ 6,377$, comprising $\$ 2,782$ for medical and $\$ 3,595$ for pharmacy claims. The largest component of the incremental increase in pharmacy costs was for medications to treat anemia and neutropenia (mean increase, \$3226; Figure 1). These medications included epoetin alfa, darbepoetin, filgastrim, and eltrombopag. The increase in non-drug-related charges was greatest in patients who completed only 12 weeks of PEG-IFN-alfa/ribavirin treatment (mean: \$6,015; range: $-28,831$ to 291,838 ) and least in patients who completed the 48-week treatment (mean: \$291; range: $-208,060$ to 95,782 ).

Two hundred two patients (15.9\%) discontinued PEG-IFN-alfa/ribavirin treatment by 12 weeks. The mean incremental TEC charge for this group was $\$ 7,509$ (range: $-29,273$ to 292,904 ). The mean incremental charge was $\$ 8,202$ (range: $-57,384$ to 226,864 ) in the 423 patients who continued treatment for between 25 and 47 weeks and $\$ 6,249$ (range: $-207,548$ to 130,297 ) in the 372 patients who completed 48 weeks of PEG-IFN-alfa/ ribavirin treatment (Figure 2).

Considering all study subjects, $14.2 \%$ discontinued treatment before week 12, 32.8\% before week 24, and $70.7 \%$ before week 48 (Table 3 ). In a sensitivity analysis restricted to 238 patients for whom HCV GT was known, 81.1\% $(\mathrm{n}=193)$ had GT-1/4/6 and therefore these patients should have received 48 weeks of PEG-IFN-alfa/ribavirin. In this group of 193 patients, $14.5 \%$ discontinued treatment before week 12, 31.6\% before week 24, and $62.7 \%$ before week 48 . In a second sensitivity analysis restricted to patients treated beyond 28 weeks, and therefore presumed to have predominately GT-1 infection, $39.8 \%$ discontinued PEG-IFN-alfa/ribavirin treatment before week 48 .

\section{Discussion}

In an insured US cohort with chronic HCV infection who were treated with PEG-IFN-alfa/ribavirin, most patients experienced one or more TEC. The most commonly identified TECs were anemia, fatigue, depression, and neutropenia. Anemia was identified in 29.2\% of patients in this study, compared with in $22 \%$ of patients in clinical trials. Rates of several adverse events including fatigue (16\%), insomnia (9\%), and depression (12\%) were lower than those observed in clinical trials $(54 \%, 37 \%$, $22 \%$, respectively) [10]. This may be expected since patients in clinical practice are typically monitored less aggressively than those in clinical trials. We used ICD-9-CM codes to identify TECs, and thus we only identified events that warranted an interaction with the healthcare system in the form of an office visit, hospitalization, or prescription. In addition, even when identified clinically, ICD-9-CM codes may not be recorded for less-severe events. As a result, the frequency and cost of TECs we report may be underestimated.

Despite this likely downward bias, we estimated that TECs increased direct treatment costs by $25 \%(\$ 6,377)$, with just over half of charges from prescription medications and the rest from office visits, hospitalizations, and other nonprescription charges. Although we did not assess indirect costs in this study, several of the TECs (e.g., anemia, depression, and insomnia) experienced by patients who receive PEG-IFN-alfa/ribavirin therapy have associated indirect costs. For example, in studies of patients with anemia due to chronic kidney disease, hemoglobin values were positively correlated with days worked [26,27]. In a study that reviewed healthcare claims from employees at a major US corporation, nearly $20 \%$ of the costs of depressive illness were related to disability, and this study did not take into account lost productivity or sick leave [28]. Depressed individuals took significantly more 
Table 2 Frequency of various treatment-emergent comorbid events ${ }^{\mathrm{a}}$ in insured patients initiating PEG-IFN-alfa and ribavirin treatment for chronic HCV infection

\begin{tabular}{|c|c|c|c|}
\hline Variable & $\begin{array}{l}\text { No. }(\%) \text { with treatment-emergent } \\
\text { comorbid event in the preindex period }\end{array}$ & $\begin{array}{l}\text { No. }(\%) \text { with treatment-emergent } \\
\text { comorbid event in the postindex period }\end{array}$ & $\begin{array}{l}\text { No. (\%) diagnosed with a new } \\
\text { treatment-emergent comorbid } \\
\text { event in the postindex period }\end{array}$ \\
\hline & $(n=1269)$ & $(n=1269)$ & $(n=1269)$ \\
\hline $\begin{array}{l}\text { Any treatment-related } \\
\text { comorbid event }\end{array}$ & $803(63.3)$ & $923(72.7)$ & $782(61.6)$ \\
\hline Blood & $182(14.3)$ & $523(41.2)$ & $446(35.2)$ \\
\hline Anemia & $147(11.6)$ & $461(36.3)$ & $371(29.2)$ \\
\hline Neutropenia & $18(1.42)$ & $144(11.4)$ & $139(11.0)$ \\
\hline Thrombocytopenia & $46(3.62)$ & $101(7.96)$ & $85(6.70)$ \\
\hline Gastrointestinal & $114(8.98)$ & $175(13.8)$ & $152(12.0)$ \\
\hline Nausea/vomiting & $78(6.15)$ & $124(9.77)$ & $106(8.35)$ \\
\hline Diarrhea & $55(4.33)$ & $75(5.91)$ & $63(4.96)$ \\
\hline Endocrine & $317(25.0)$ & $354(27.9)$ & $154(12.1)$ \\
\hline Diabetes & $214(16.9)$ & $217(17.1)$ & $61(4.81)$ \\
\hline Hyperthyroidism & $20(1.58)$ & $30(2.36)$ & $26(2.05)$ \\
\hline Hypothyroidism & $117(9.22)$ & $164(12.9)$ & $88(6.93)$ \\
\hline Psychiatric & $262(20.7)$ & $375(29.6)$ & $255(20.1)$ \\
\hline Depression & $181(14.3)$ & $266(21.0)$ & $146(11.5)$ \\
\hline Anxiety disorders & $48(3.78)$ & $54(4.26)$ & $31(2.44)$ \\
\hline Bipolar disorders & $22(1.73)$ & $27(2.13)$ & $17(1.34)$ \\
\hline Insomnia & $82(6.46)$ & $143(11.3)$ & $114(8.98)$ \\
\hline Skin and subcutaneous & $59(4.65)$ & $119(9.38)$ & $111(8.75)$ \\
\hline Alopecia & $11(0.87)$ & $17(1.34)$ & $15(1.18)$ \\
\hline Skin rash & $49(3.86)$ & $103(8.12)$ & $97(7.64)$ \\
\hline Other disorders & $383(30.2)$ & $423(33.3)$ & $311(24.5)$ \\
\hline Dyspnea & $91(7.17)$ & $98(7.72)$ & 76 (5.99) \\
\hline Fatigue & $270(21.3)$ & $319(25.1)$ & $208(16.4)$ \\
\hline Headache & 96 (7.57) & $100(7.88)$ & 75 (5.91) \\
\hline
\end{tabular}

$\mathrm{HCV}$, hepatitis C virus; PEG-IFN-alfa, pegylated interferon alpha.

${ }^{a}$ ICD-9-CM diagnosis code for listed events appearing in any diagnosis field.

${ }^{b}$ Event appears during period when patient is being treated but not in pretreatment period.

time off work than those with diabetes, heart disease, or back problems [28]. In addition, absenteeism and disability expenditures were higher in individuals with insomnia than those without it [29]. Together these studies suggest that indirect costs of these TECs are likely to be significant.

Shortened treatment duration was not associated with a reduced cost of treating TECs. Nonprescription costs accounted for most of the total costs in patients who stopped treatment by 12 weeks and between 24 and 48 weeks, suggesting that these groups of patients frequently experience TECs. The lowest cost of treating TECs was for patients who stopped treatment between 13 and 24 weeks; most of these patients probably discontinued treatment because they completed treatment for GT 2/3 infection rather than because of TECs. Patients who completed therapy at 48 weeks had the lowest nonprescription costs but high prescription costs, possibly indicating stable management of TECs such as anemia or neutropenia with costly growth factors.

Although comparisons to other studies are difficult because of differences in methodology, the mean treatment duration of 215 days is consistent with estimates from other studies of $172-240$ days $[15,16,19,30]$. In a retrospective cohort study of Veterans Affairs patients, two of the most common TECs we identified, anemia and neutropenia, were associated with lower persistence with PEG-IFN-alfa/ ribavirin treatment (mean 172 days) [30]. Similar to patients in our study, the investigators identified patients with anemia and neutropenia through both ICD-9-CM codes and by identifying medication use (specifically the use of growth factors). Growth factors may improve treatment 


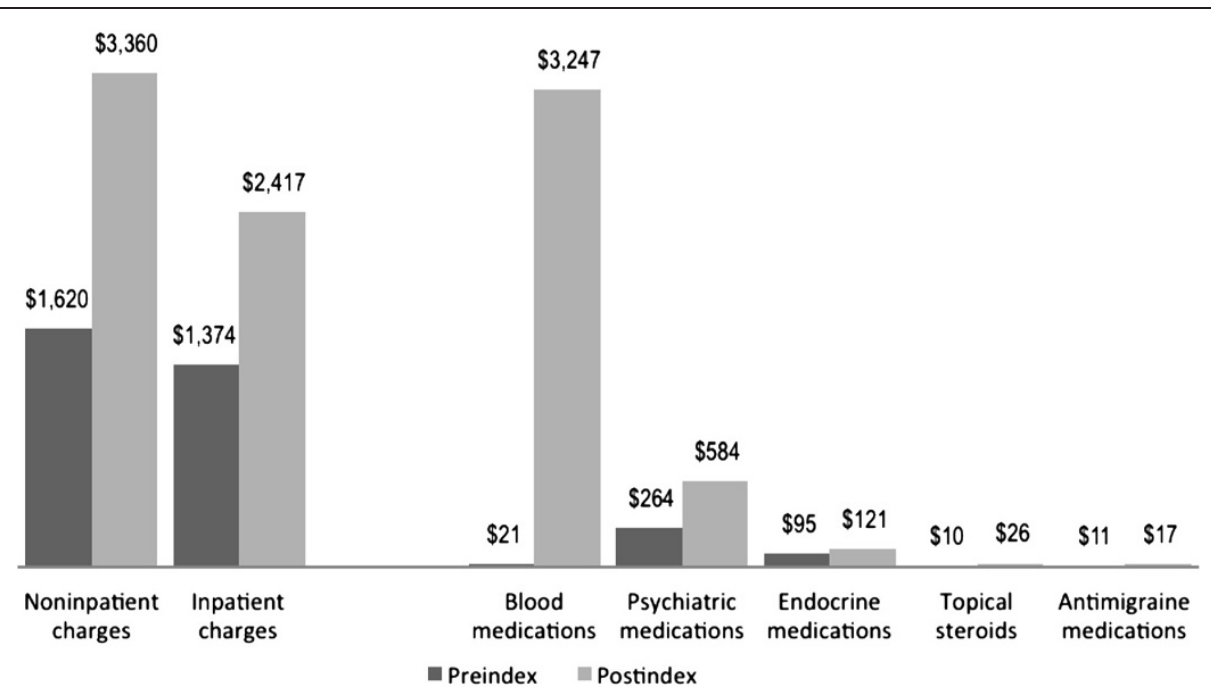

Figure 1 Increase in non-medication-related and medication-related charges for treatment-emergent comorbid events between preindex and postindex periods.

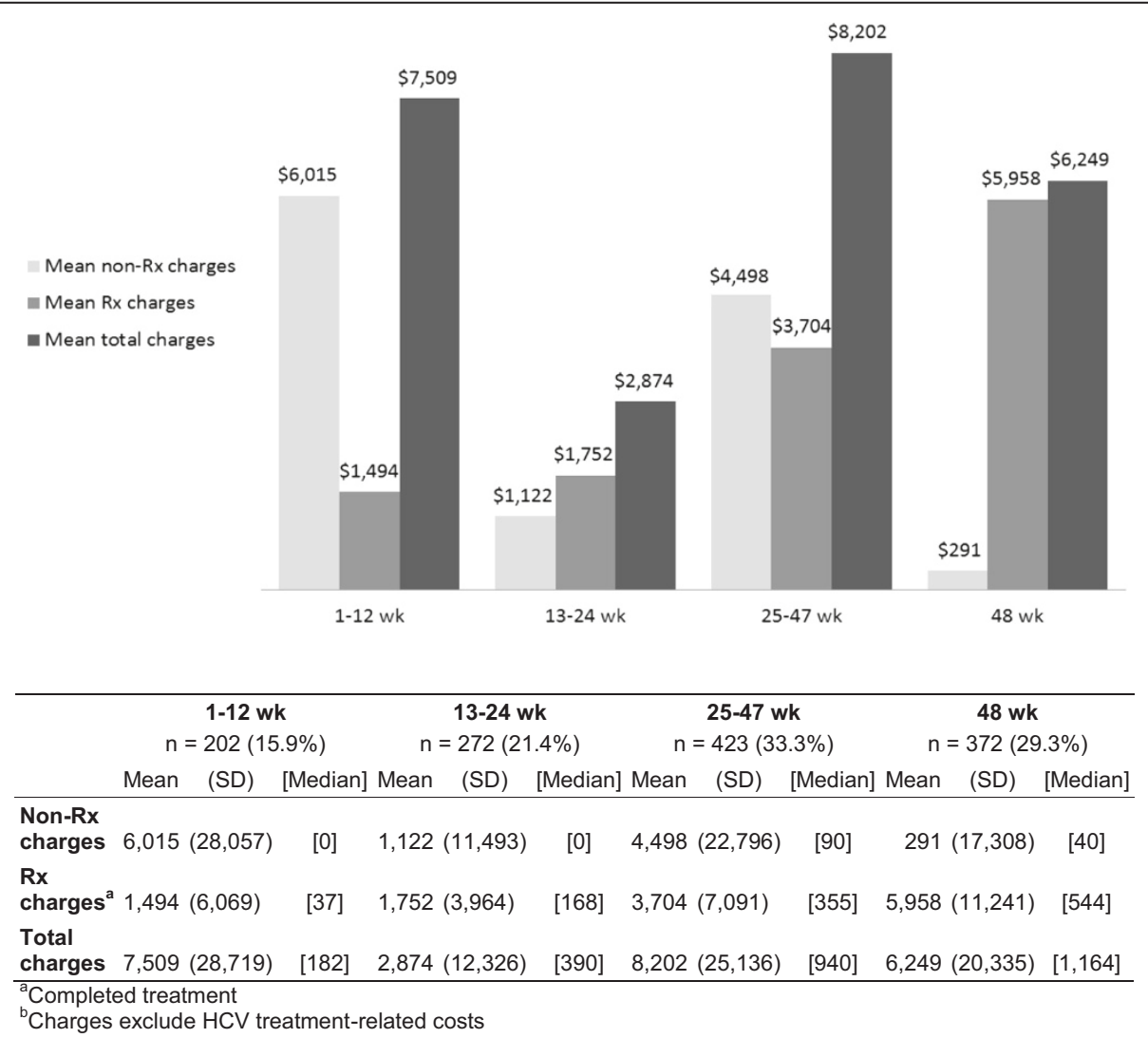

Figure 2 Increase in charges from 1-year preindex to 1-year postindex periods for treatment-related comorbid events, by treatment duration. Data on four mutually exclusive groups are presented: those who discontinued PEG-IFN-alfa/ribavirin between weeks 1-12, weeks 13-24, weeks 25-47, and after week 47. For all groups, annual charges are shown. 
Table 3 Duration and discontinuation of PEG-IFN-alfa/ribavirin therapy in insured patients receiving treatment for chronic HCV infection

\begin{tabular}{|c|c|c|c|c|c|c|c|c|c|c|}
\hline \multirow[t]{2}{*}{ Patient group } & \multirow[b]{2}{*}{ No. of patients } & \multicolumn{3}{|c|}{$\begin{array}{c}\text { Duration of PEG-IFN-alfa/ribavirin } \\
\text { therapy (days) }\end{array}$} & \multicolumn{2}{|c|}{$\begin{array}{l}\text { Discontinue } \\
\text { before } 12 \mathrm{wk}\end{array}$} & \multicolumn{2}{|c|}{$\begin{array}{l}\text { Discontinue } \\
\text { before } 24 \text { wk }\end{array}$} & \multicolumn{2}{|c|}{$\begin{array}{r}\text { Discontinue } \\
\text { before } 48 \mathrm{wk}\end{array}$} \\
\hline & & Mean & (SD) & Median & $\mathrm{n}$ & (\%) & $n$ & (\%) & $\mathrm{n}$ & (\%) \\
\hline All & 1,269 & 214.8 & (113.8) & 195 & 180 & $(14.2)$ & 416 & (32.8) & 897 & $(70.7)$ \\
\hline Patients with known GT & 238 & 223.1 & (115.3) & 211 & 32 & (13.4) & 79 & $(33.2)$ & 165 & $(69.3)$ \\
\hline GT 2/3 & 45 & 161.3 & $(60.4)$ & 168 & 4 & $(8.9)$ & 18 & $(40.0)$ & 44 & $(97.8)$ \\
\hline GT $1 / 4 / 6$ & 193 & 237.5 & $(120.2)$ & 282 & 28 & $(14.5)$ & 61 & (31.6) & 121 & $(62.7)$ \\
\hline Patients treated $>28$ weeks $^{\mathrm{a}}$ & 618 & 315.6 & $(57.1)$ & 339 & - & - & - & - & 246 & (39.8) \\
\hline
\end{tabular}

GT, genotype; HCV, hepatitis C virus; PEG-IFN-alfa, pegylated interferon alpha.

apresumed to have predominately GT-1 infection.

tolerability and thus enhance persistence. Dissimilarities in data sources, clinical care settings, data analysis techniques, and patient characteristics may explain some of the differences in the treatment discontinuation estimates. Although we could not distinguish between patients who discontinued therapy because of adverse events and those who discontinued therapy because of lack of virologic response, our findings support the concept that adverse events lead to high rates of therapy discontinuation.

Limitations of this study include those common to claims analysis. A commercially insured population may not be representative of the entire US population nor of treatment patterns in other countries. Lack of clinical data can confound interpretation. In particular, $\mathrm{HCV}$ treatment duration is dictated by GT, which was unavailable for most patients in this study. HCV GT was available for a subset of 238 patients. In this subset, $81 \%$ had GT $1 / 4 / 6$, which is similar to other US cohorts, suggesting that our data are representative of the US population [31,32]. According to standard treatment recommendations, these patients with predominately GT-1 would be expected to complete 48 weeks of treatment [33]. This subset of patients had discontinuation rates that were similar to the overall group, which suggests that our assumption that treatment duration was indicative of GT was reasonable. Furthermore, response guided therapy would lead some patients to have treatment recommended beyond 48 weeks. If these patients continued treatment up to 48 weeks, they might be clinically discontinuing therapy prematurely, whereas in our analysis they would not be considered to have done so. Conversely, discontinuation of therapy may be recommended when virologic response is poor, and we could not distinguish between this and TECs as a cause of discontinuation. This study was intended to examine only one aspect of cost, not total treatment costs or cost effectiveness. HCV treatment with PEG-IFN-alfa/ribavirin costs between $\$ 23,000$ and $\$ 78,000$ per year, and newer treatments are substantially more expensive [17]. Given the timing of this study, none of the patients were treated with newer direct acting antivirals.

In an additional sensitivity analysis of the patients who stopped therapy after 28 weeks and were thus presumed to have GT $1 / 4 / 6,40 \%$ stopped before completing the recommended duration of therapy. Patients treated over 12 weeks with GT-1 would be expected to have had a virologic response [33] and thus discontinuations after 24 weeks would most likely be due to adverse events in those with GT-1. Overall, these sensitivity analyses further support the idea that discontinuation rates in patients treated with PEG-IFN-alfa/ribavirin are high and frequently due to TECs.

Additional limitations include miscoding or undercoding of claims, which may affect the accuracy of cost estimates. Finally, although we were only able to study patients who were receiving double therapy, the cost of TECs may rise with the use of triple therapy (PEG-IFN-alfa/ ribavirin plus a protease inhibitor) because gastrointestinal events, skin rash, and anemia are more common with triple therapy than with PEG-IFN-alfa/ribavirin alone $[10,14,34]$.

\section{Conclusion}

Treatment of chronic HCV infection with PEG-IFN-alfa/ ribavirin led to frequent TECs and that these events were associated with significant costs. Furthermore, nearly half of treated patients discontinued therapy. It is likely that adding a protease inhibitor to the PEG-IFNalfa/ribavirin treatment discussed in this study will result in similar or increased TECs. Thus, better-tolerated therapies associated with fewer TECs that reduce healthcare system costs and improve patient continuation rates are needed.

\section{Competing interests}

Sandhya Sapra and Gilbert L'Italien are employees of Bristol-Myers Squibb Company, which provided funding for this study. Eunice Chang and Michael Broder are employees of Partnership for Health Analytic Research, which was paid by Bristol-Myers Squibb Company to conduct the research described in this manuscript. 


\section{Authors' contributions}

SS was involved in conception and design, analysis and interpretation, drafting and revision of the manuscript, and final approval of the manuscript. EC served as a statistician and was involved in conception and design, statistical analysis and interpretation, revision of the manuscript, and final approval of the manuscript. MSB was involved in conception and design, analysis and interpretation, drafting and revision of the manuscript, and final approval of the manuscript. GL'l was involved in conception and design, drafting and revision of the manuscript, and final approval of the manuscript.

\section{Acknowledgements}

This study was funded by Bristol-Myers Squibb Company. Partnership for Health Analytic Research, LLC (PHAR, LLC) was paid by Bristol-Myers Squibb Company to conduct the research described in this manuscript.

\section{Author details}

'Bristol-Myers Squibb, 1146 Lawrenceville Road, Lawrenceville, NJ, USA. ${ }^{2}$ Partnership for Health Analytic Research, LLC, 280 S. Beverly Drive, Suite 404, Beverly Hills, CA, USA. ${ }^{3}$ Yale University School of Medicine, 333 Cedar Street, New Haven, CT, USA.

Received: 14 March 2014 Accepted: 11 September 2014

Published: 24 September 2014

\section{References}

1. Lavanchy D: The global burden of hepatitis C. Liver Int 2009, 29(Suppl 1):74-81

2. Spiegel BM, Younossi ZM, Hays RD, Revicki D, Robbins S, Kanwal F: Impact of hepatitis $C$ on health related quality of life: a systematic review and quantitative assessment. Hepatology 2005, 41:790-800.

3. Clark PJ, Muir AJ: Overcoming barriers to care for hepatitis C. N Engl J Med 2012, 366:2436-2438.

4. Volk ML, Tocco R, Saini S, Lok AS: Public health impact of antiviral therapy for hepatitis C in the United States. Hepatology 2009, 50:1750-1755.

5. Armstrong GL, Wasley A, Simard EP, McQuillan GM, Kuhnert WL, Alter MJ: The prevalence of hepatitis C virus infection in the United States, 1999 through 2002. Ann Intern Med 2006, 144:705-714.

6. Fried MW, Shiffman ML, Reddy KR, Smith C, Marinos G, Gonçales FL Jr, Häussinger D, Diago M, Carosi G, Dhumeaux D, Craxi A, Lin A, Hoffman J, Yu J: Peginterferon alfa-2a plus ribavirin for chronic hepatitis $C$ virus infection. N Engl J Med 2002, 347:975-982

7. Manns MP, McHutchison JG, Gordon SC, Rustgi VK, Shiffman M, Reindollar R, Goodman ZD, Koury K, Ling M, Albrecht JK: Peginterferon alfa-2b plus ribavirin compared with interferon alfa-2b plus ribavirin for initial treatment of chronic hepatitis C: a randomised trial. Lancet 2001, 358:958-965.

8. Swain MG, Lai MY, Shiffman ML, Cooksley WG, Zeuzem S, Dieterich DT, Abergel A, Pessôa MG, Lin A, Tietz A, Connell EV, Diago M: A sustained virologic response is durable in patients with chronic hepatitis $C$ treated with peginterferon alfa-2a and ribavirin. Gastroenterology 2010, 139:1593-1601.

9. Veldt BJ, Heathcote EJ, Wedemeyer H, Reichen J, Hofmann WP, Zeuzem S, Manns MP, Hansen BE, Schalm SW, Janssen HL: Sustained virologic response and clinical outcomes in patients with chronic hepatitis $C$ and advanced fibrosis. Ann Intern Med 2007, 147:677-684.

10. Fried MW: Side effects of therapy of hepatitis $C$ and their management. Hepatology 2002, 36:S237-S244.

11. McHutchison JG, Manns M, Patel K, Poynard T, Lindsay KL, Trepo C, Dienstag J, Lee WM, Mak C, Garaud JJ, Albrecht JK: Adherence to combination therapy enhances sustained response in genotype-1-infected patients with chronic hepatitis C. Gastroenterology 2002, 123:1061-1069.

12. O'Brien TR: Interferon-alfa, interferon-lambda and hepatitis C. Nat Genet 2009, 41:1048-1050.

13. Poordad F, McCone J Jr, Bacon BR, Bruno S, Manns MP, Sulkowski MS, Jacobson IM, Reddy KR, Goodman ZD, Boparai N, DiNubile MJ, Sniukiene V, Brass CA, Albrecht JK, Bronowicki JP, SPRINT-2 Investigators: Boceprevir for untreated chronic HCV genotype 1 infection. N Engl J Med 2011, 364:1195-1206.

14. Jacobson IM, McHutchison JG, Dusheiko G, Di Bisceglie AM, Reddy KR, Bzowej NH, Marcellin P, Muir AJ, Ferenci P, Flisiak R, George J, Rizzetto M, Shouval D, Sola R, Terg RA, Yoshida EM, Adda N, Bengtsson L, Sankoh AJ, Kieffer TL, George S, Kauffman RS, Zeuzem S, ADVANCE Study Team:
Telaprevir for previously untreated chronic hepatitis $C$ virus infection. N Engl J Med 2011, 364:2405-2416.

15. Beste LA, loannou GN, Larson MS, Chapko M, Dominitz JA: Predictors of early treatment discontinuation among patients with genotype 1 hepatitis $C$ and implications for viral eradication. Clin Gastroenterol Hepatol 2010, 8:972-978.

16. Butt AA, McGinnis KA, Skanderson M, Justice AC: Hepatitis C treatment completion rates in routine clinical care. Liver Int 2010, 30:240-250.

17. Average Wholesale Price: PriceRx Pro [electronic database]. Wolters Kluwer Health. 2013, https://pricerx.medispan.com. Accessed 9/27/2013.

18. Salomon JA, Weinstein MC, Hammitt JK, Goldie SJ: Cost-effectiveness of treatment for chronic hepatitis $C$ infection in an evolving patient population. JAMA 2003, 290:228-237.

19. Mitra D, Davis KL, Beam C, Medjedovic J, Rustgi V: Treatment patterns and adherence among patients with chronic hepatitis $C$ virus in a US managed care population. Value Health 2010, 13:479-486.

20. Zeuzem S: Interferon-based therapy for chronic hepatitis C: current and future perspectives. Nat Clin Pract Gastroenterol Hepatol 2008, 5:610-622.

21. PegIntron (peginterferon alfa-2b) Injection, Powder for Solution for Subcutaneous Use [package insert]. Whitehouse Station, NJ: Merck \& Co., Inc; 2011.

22. PEGASYS (peginterferon alfa-2a) Injection for Subcutaneous Use [package insert]. Package Insert. South San Francisco, CA: Genentech, Inc; 2011.

23. COPEGUS ${ }^{\oplus}$ (ribavirin) tablets [package insert]. South San Francisco, CA Genentech, Inc; 2011.

24. Ribasphere (ribavirin, USP) tablets [package insert]. New York, NY: Kadmon Pharmaceuticals; 2012

25. Hwang W, Weller W, Ireys H, Anderson G: Out-of-pocket medical spending for care of chronic conditions. Health Aff (Millwood) 2001, 20:267-278.

26. Papatheofanis F, Bookhart BK, Muser E, Piech CT: An examination of productivity and resource utilization associated with epoetin alfa treatment in employees with predialysis chronic kidney disease. J Occup Environ Med 2008, 50:584-589.

27. Kimel M, Leidy NK, Mannix S, Dixon J: Does epoetin alfa improve health-related quality of life in chronically ill patients with anemia? Summary of trials of cancer, HIV/AIDS, and chronic kidney disease. Value Health 2008, 11:57-75.

28. Druss BG, Rosenheck RA, Sledge WH: Health and disability costs of depressive illness in a major U.S. corporation. Am J Psychiatry 2000, 157:1274-1278.

29. Ozminkowski RJ, Wang S, Walsh JK: The direct and indirect costs of untreated insomnia in adults in the United States. Sleep 2007, 30:263-273.

30. Iqbal SU, Cunningham F, Lee A, Miller DR, Li NC, Cheung R, Kazis L: Persistence with hepatitis $C$ therapy in the Department of Veterans Affairs. J Clin Pharm Ther 2008, 33:251-261.

31. Zein NN, Rakela J, Krawitt EL, Reddy KR, Tominaga T, Persing DH: Hepatitis $C$ virus genotypes in the United States: epidemiology, pathogenicity, and response to interferon therapy. Collaborative Study Group. Ann Intern Med 1996, 125:634-639.

32. Hyams KC, Riddle J, Rubertone M, Trump D, Alter MJ, Cruess DF, Han X, Nainam OV, Seeff LB, Mazzuchi JF, Bailey S: Prevalence and incidence of hepatitis $C$ virus infection in the US military: a seroepidemiologic survey of 21,000 troops. Am J Epidemiol 2001, 153:764-770.

33. Strader DB, Wright T, Thomas DL, Seeff $L B$, American Association for the Study of Liver Diseases: Diagnosis, management, and treatment of hepatitis C. Hepatology 2004, 39:1147-1171.

34. Zeuzem S, Andreone P, Pol S, Lawitz E, Diago M, Roberts S: Telaprevir for retreatment of HCV infection. N Engl J Med 2011, 364:2417-2428.

doi:10.1186/1472-6963-14-429

Cite this article as: Sapra et al:: Incidence and cost of treatmentemergent comorbid events in insured patients with chronic hepatitis $C$ virus infection: a retrospective cohort study. BMC Health Services Research 2014 14:429 